\title{
Effect of Landiolol Hydrochloride on Hemodynamics in a Histamine-Induced Shock Model
}

\author{
Masaharu Hirano $^{1}$ (C) Tatsuaki Okamura $^{2} \cdot$ Tetsuji Nagano $^{3} \cdot$ Shigeyuki Nonaka $^{3} \cdot$ Tsutomu Shiroya $^{3}$
}

Accepted: 31 May 2021 / Published online: 14 June 2021

(c) The Author(s) 2021

\begin{abstract}
Background and Objective Anaphylactic shock is a serious adverse drug reaction that can occur in response to contrast media used during coronary computed tomography angiography. The imaging quality of coronary computed tomography angiography is improved by $\beta$-blockers, which decrease heart rate. In this study, we sought to analyze anaphylactic shock treatment in patients receiving short-acting $\beta 1$-blockers.

Methods We examined the influence of epinephrine and glucagon on hemodynamics during $\beta$-blocker treatment, using a dog histamine shock model; the $\beta 1$-blocker landiolol hydrochloride was used. The effects of these drugs were assessed by recording changes relative to established baselines.

Results Histamine and landiolol decreased mean blood pressure. Histamine exerted no apparent effect on heart rate, whereas landiolol decreased heart rate. Further, landiolol reduced histamine-mediated increases in the force of cardiac contraction. Increasing the doses of epinephrine and glucagon ameliorated anaphylactic shock-induced deterioration in hemodynamic parameters in subjects receiving landiolol.

Conclusions In patients receiving landiolol for coronary computed tomography angiography, deterioration in hemodynamic parameters due to anaphylactic shock can be mitigated by increasing the doses of epinephrine and glucagon. Clinicians should thus prepare appropriate amounts of epinephrine and glucagon prior to coronary computed tomography angiography.
\end{abstract}

\section{Key Points}

Anaphylactic shock should be treated with epinephrine

The effects of epinephrine may be reduced in patients receiving $\beta$-blockers

Shock symptoms can be ameliorated by increasing epinephrine and glucagon doses
Masaharu Hirano

m-hirano@tokyo-med.ac.jp

1 Department of Cardiology, Tokyo Medical University, 6-7-1, Nishi-shinjuku, Shinjuku-ku, Tokyo 160-0023, Japan

2 Clinical Development Planning, Ono Pharmaceutical Co., Ltd, Osaka, Japan

3 Minase Research Institute of Ono Pharmaceutical, Osaka, Japan

\section{Introduction}

Treatment guidelines recommend the use of $\beta$-adrenergic receptor blockers ( $\beta$-blockers) for patients diagnosed with or suspected to have ischemic heart disease, with the goal of improving long-term prognosis [1-4]. Coronary computed tomography angiography (CCTA) is a non-invasive method for diagnosing the existence and extent of coronary stenosis in such patients [5, 6]. Single-center and multi-center studies have shown CCTA to be useful, with very high negative predictive values $[7,8]$. However, computed tomography image quality is degraded in patients with high heart rates, thus requiring administration of $\beta$-blockers, which reduce heart rate and improve the image quality by increasing the relative time resolution during CCTA [5, 6]. Many clinical and nonclinical studies of CCTA have administered $\beta$-blockers to reduce heart rate during CCTA $[7,8]$. The pharmacokinetic profile of landiolol reveals that this compound has high $\beta 1$ selectivity and a very short circulating half-life (3.97 $\mathrm{min})$ [9]. Consequently, it can be used as a $\beta$-blocking agent to increase the diagnosable proportion of patients undergoing CCTA because it decreases the effect of motion artifacts 
induced by the heart rate and does not exhibit a prolonged $\beta$-blocking effect after examination [10-13].

Anaphylactic shock is a serious adverse drug reaction that can occur in response to contrast media used in multi-detector computed tomography [14]. It is attributed in part to contrast media-induced histamine release from mast cells $[15,16]$. Anaphylactic shock presents with various clinical symptoms including a rapid decrease in blood pressure, airway constriction, and urticaria. It is treated similarly to anaphylaxis [14]. Upon occurrence of anaphylactic shock, prompt administration of adrenaline is required [17]. Adrenaline exerts peripheral vasoconstrictive and cardiotonic actions, as well as bronchial dilatation and histamine release inhibition. It is the first-choice drug for emergency care for anaphylactic shock. Patients taking $\beta$-blockers are highly refractory to standard treatments for various symptoms of anaphylaxis; moreover, their symptoms tend to be aggravated [18]. Glucagon is effective in cases in which adrenaline is ineffective [17].

In this study, we sought to determine the effect of landiolol on contrast media-induced anaphylactic shock. To this end, we assessed the effect of landiolol on histamineinduced changes in blood pressure, heart rate, and cardiac contraction; epinephrine-mediated antagonism of histamine action (reduction in blood pressure and diminution of cardiac contraction); and glucagon-mediated antagonism of histamine action (diminution of cardiac contraction).

\section{Methods}

\subsection{Materials}

Landiolol hydrochloride was procured from Ono Pharmaceutical Co., Ltd. (Osaka, Japan) and stored at $-20^{\circ} \mathrm{C}$ (acceptable range: -30 to $-10^{\circ} \mathrm{C}$ ). Histamine dihydrochloride was procured from Sigma-Aldrich and stored at $5{ }^{\circ} \mathrm{C}$ (acceptable range: $1-9^{\circ} \mathrm{C}$ ). Epinephrine was procured from Daiichi-Sankyo Co., Ltd. and stored at room temperature (acceptable range: $1-30{ }^{\circ} \mathrm{C}$ ) under light-shielded conditions. Glucagon was procured from Eisai and stored at $5{ }^{\circ} \mathrm{C}$ (acceptable range: $1-9{ }^{\circ} \mathrm{C}$ ) under light-shielded conditions. Veterinary pentobarbital (Schering-Plough Animal Health) was used for anesthesia.

\subsection{Animal Preparation}

Male beagles ( $n=18$; Kitayama Labes Co., Ltd), weighing between $10.71 \mathrm{~kg}$ and $14.37 \mathrm{~kg}$, were used. After weighing, beagles were anesthetized with a single intravenous dose of pentobarbital $(30 \mathrm{mg} / \mathrm{kg})$. Their artificial respiration was maintained at a tidal volume of $200 \mathrm{~mL} / \mathrm{breath}$ and a respiratory rate of 15 breaths/min using a respirator
(SN-480-3; Shinano Manufacturing Co., Ltd). Anesthesia was maintained by continuous intravenous administration of pentobarbital $(5-7 \mathrm{mg} / \mathrm{kg} / \mathrm{h})$ adjusted to maintain stable hemodynamics (blood pressure, heart rate, cardiac contraction $[\mathrm{LVdP} / \mathrm{d} t])$. Experimental room temperature was $24 \pm$ $2{ }^{\circ} \mathrm{C}$ during the experiment. All animal experiments were approved by the Ethical Committee of Ono Pharmaceutical Co., Ltd. All methods were performed in accordance with approved guidelines.

\subsection{Hemodynamic Evaluation}

Right carotid pressure was measured by inserting a catheter sheath ( $7 \mathrm{Fr} \times 1 \mathrm{~cm}$; Medikit Co., Ltd.) into the right carotid artery. Left ventricular pressure was measured by inserting an angiography catheter (ST60BM3.07N; Medikit Co., Ltd.) into the left ventricle. In each case, the catheter sheath was connected to fluid-filled blood pressure extension tubing that was connected to a pressure transducer (DX-100; Nihon Kohden Corporation) and an amplifier (AP-601G; Nihon Kohden Corporation) for continuous monitoring of left ventricular pressure. Cardiac contraction was measured using a differential calculus arithmetic unit (SS-1017; Nihon Kohden Corporation), and heart rate was measured using a heart rate meter (AT-601G; Nihon Kohden Corporation). All data were acquired using a circulatory dynamics analysis system (MP/VAS3 Ver.1.0R98b5; Physio-Tech Co., Ltd.).

\subsection{Protocols}

\subsubsection{Effect of Landiolol on the Action of Histamine}

The following procedures were performed on the same dogs under pentobarbital anesthesia: (1) sequential single doses of histamine ( 2 and $6 \mu \mathrm{g} / \mathrm{kg}, 0.5 \mathrm{~mL} / \mathrm{kg}$ ) were intravenously administered in the absence of landiolol (normal saline was administered as a vehicle control) to measure the influence of histamine alone on blood pressure, heart rate, and cardiac contractions and (2) sequential single doses of histamine (2 and $6 \mu \mathrm{g} / \mathrm{kg}, 0.5 \mathrm{~mL} / \mathrm{kg}$ ) were intravenously administered in the presence of landiolol (intravenous continuous doses of 3 , 10 , or $30 \mu \mathrm{g} / \mathrm{kg} / \mathrm{min}, 0.6 \mathrm{~mL} / \mathrm{kg} / \mathrm{h}$ ) to investigate the effect of landiolol on the actions of histamine. Drug effects were assessed using changes relative to baseline.

\subsubsection{Effect of Landiolol on Epinephrine-Mediated Antagonism of Histamine}

The following procedures were performed on the same dogs under pentobarbital anesthesia: (1) concurrent single doses of histamine $(6 \mu \mathrm{g} / \mathrm{kg}, 0.5 \mathrm{~mL} / \mathrm{kg})$, normal saline, and epinephrine $(0.3$ or $3 \mu \mathrm{g} / \mathrm{kg}, 0.1 \mathrm{~mL} / \mathrm{kg})$ were intravenously administered in the absence of landiolol (landiolol was 
replaced with intravenous normal saline as a vehicle control) to measure the effects of epinephrine on histamine-induced changes in blood pressure, heart rate, and cardiac contraction and (2) concurrent single doses of histamine $(6 \mu \mathrm{g} / \mathrm{kg}$, $0.5 \mathrm{~mL} / \mathrm{kg})$, normal saline, and epinephrine $(0.3,1$, or $3 \mu \mathrm{g} /$ $\mathrm{kg}, 0.1 \mathrm{~mL} / \mathrm{kg}$ ) were intravenously administered in the presence of landiolol (intravenous continuous dose of $10 \mu \mathrm{g} / \mathrm{kg} /$ $\min , 0.6 \mathrm{~mL} / \mathrm{kg} / \mathrm{h}$ ) to determine the effect of landiolol on epinephrine-mediated antagonism of histamine. Drug effects were assessed using changes relative to baseline.

\subsubsection{Effect of Landiolol on Glucagon-Mediated Antagonism of Histamine}

The following procedures were performed on the same dogs under pentobarbital anesthesia: (1) concurrent single doses of histamine $(6 \mu \mathrm{g} / \mathrm{kg}, 0.5 \mathrm{~mL} / \mathrm{kg})$ were intravenously administered to each beagle during continuous intravenous administration of normal saline or glucagon $(0.3 \mu \mathrm{g} / \mathrm{kg} /$ $\min , 1.8 \mathrm{~mL} / \mathrm{kg} / \mathrm{h}$ ) in the absence of landiolol (replaced by continuous normal saline administration) to measure the effect of glucagon on histamine-induced changes in cardiac contraction and heart rate and (2) concurrent single doses of histamine $(6 \mu \mathrm{g} / \mathrm{kg}, 0.5 \mathrm{~mL} / \mathrm{kg})$ were intravenously administered during continuous intravenous administration of glucagon $(0.3$ or $30 \mu \mathrm{g} / \mathrm{kg} / \mathrm{min}, 1.8 \mathrm{~mL} / \mathrm{kg} / \mathrm{h})$ in the presence of landiolol (continuous intravenous dose of $3 \mu \mathrm{g} /$ $\mathrm{kg} / \mathrm{min}, 0.6 \mathrm{~mL} / \mathrm{kg} / \mathrm{h}$ ) to measure the effect of landiolol on glucagon-mediated antagonism of histamine. Drug effects were assessed using changes relative to baseline.

\subsection{Statistical Analyses}

Statistical analyses were performed using the SAS System Release 8.2 (SAS Institute, Tokyo, Japan) together with EXSAS Version 7.10 (Arm Systex). Data were analyzed using paired tests, and a hazard ratio $<5 \%$ was regarded as statistically significant.

\section{Results}

\subsection{Effect of Landiolol on the Action of Histamine}

In dogs under pentobarbital anesthesia, pre-histamine values for mean blood pressure, heart rate, and cardiac contraction $\left(\mathrm{LVdP} / \mathrm{d} t_{\max }\right)$ were $152.7 \pm 4.7 \mathrm{mmHg}, 176.0 \pm 6.5 \mathrm{bpm}$, and $4914.0 \pm 291.1 \mathrm{mmHg} / \mathrm{s}$, respectively. The effects of landiolol on histamine-induced changes in mean blood pressure, heart rate, and cardiac contraction are shown in Figs. 1, 2,3 .

As shown in Fig. 1, histamine ( 2 and $6 \mu \mathrm{g} / \mathrm{kg}$ ) decreased mean blood pressure in a dose-proportional manner; the respective changes caused by 2 and $6 \mu \mathrm{g} / \mathrm{kg}$ of histamine were $-18.0 \pm 3.5$ and $-45.7 \pm 6.0 \mathrm{mmHg}$. Landiolol $(3,10$, and $30 \mu \mathrm{g} / \mathrm{kg} / \mathrm{min}$ ) also decreased mean blood pressure in a dose-proportional manner; these changes were $<10 \mathrm{mmHg}$ $(-4.7 \pm 1.1,-6.5 \pm 0.8$, and $-8.2 \pm 2.6 \mathrm{mmHg}$, respectively). The mean blood pressure-lowering action of histamine ( 2 and $6 \mu \mathrm{g} / \mathrm{kg}$ ) was significantly enhanced by all doses of landiolol (3,10, and $30 \mu \mathrm{g} / \mathrm{kg} / \mathrm{min}$ ). The sum of changes in mean blood pressure induced by histamine alone $(2 \mu \mathrm{g} / \mathrm{kg}$ or $6 \mu \mathrm{g} / \mathrm{kg})$ and landiolol alone $(30 \mu \mathrm{g} / \mathrm{kg} / \mathrm{min})$ were $-26.2 \pm 3.0$ and $-53.8 \pm 6.2 \mathrm{mmHg}$, respectively. When the drugs were used in combination, the changes
Fig. 1 Effect of landiolol on the action of histamine on blood pressure $(n=6) . * P<0.05$; $* * P<0.01 ; * * * P<0.001$ (histamine vs landiolol and histamine, landiolol vs landiolol and histamine; paired $t$-test); ${ }^{\#} P<0.05$ (sum of the changes induced by landiolol alone and histamine alone vs the changes induced by combined use; paired test)

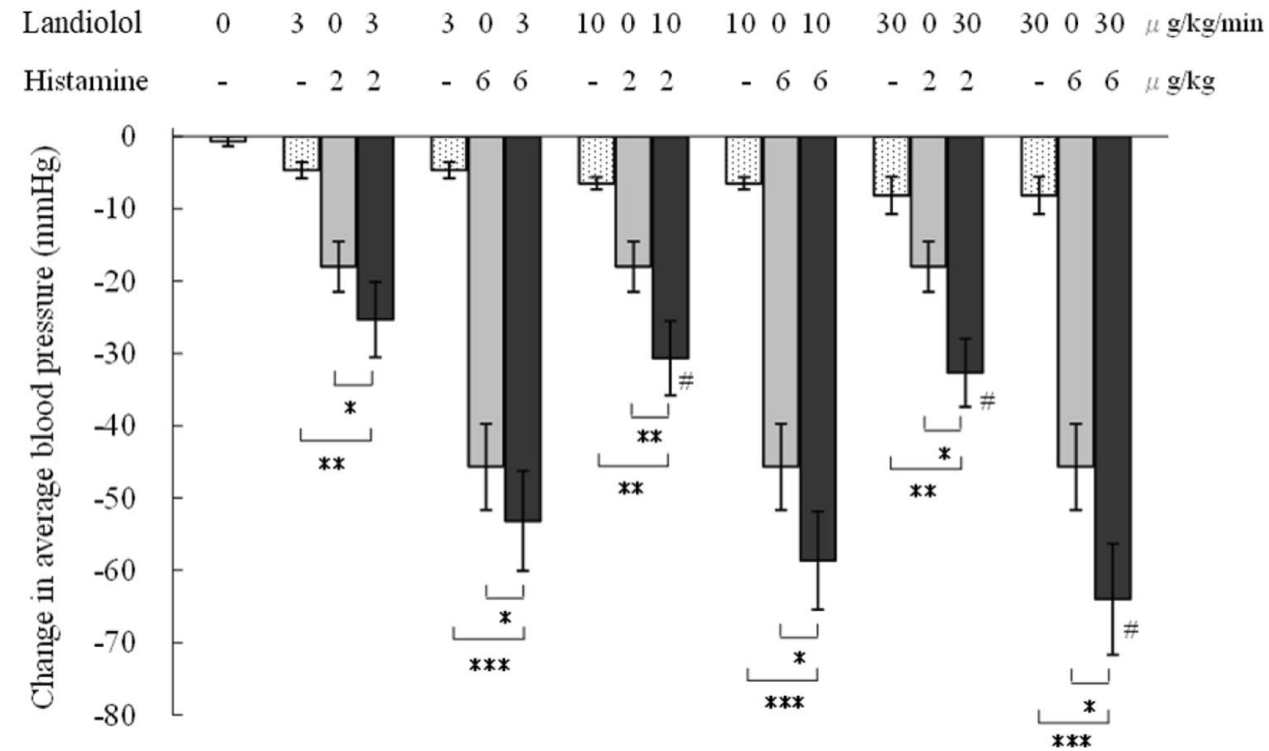


Fig. 2 Effect of landiolol on the action of histamine on heart rate $(n=6) . * P<0.05$; $* * P<0.01$; $* * * P<0.001$ (histamine vs landiolol and histamine, landiolol vs landiolol and histamine; paired $t$-test)

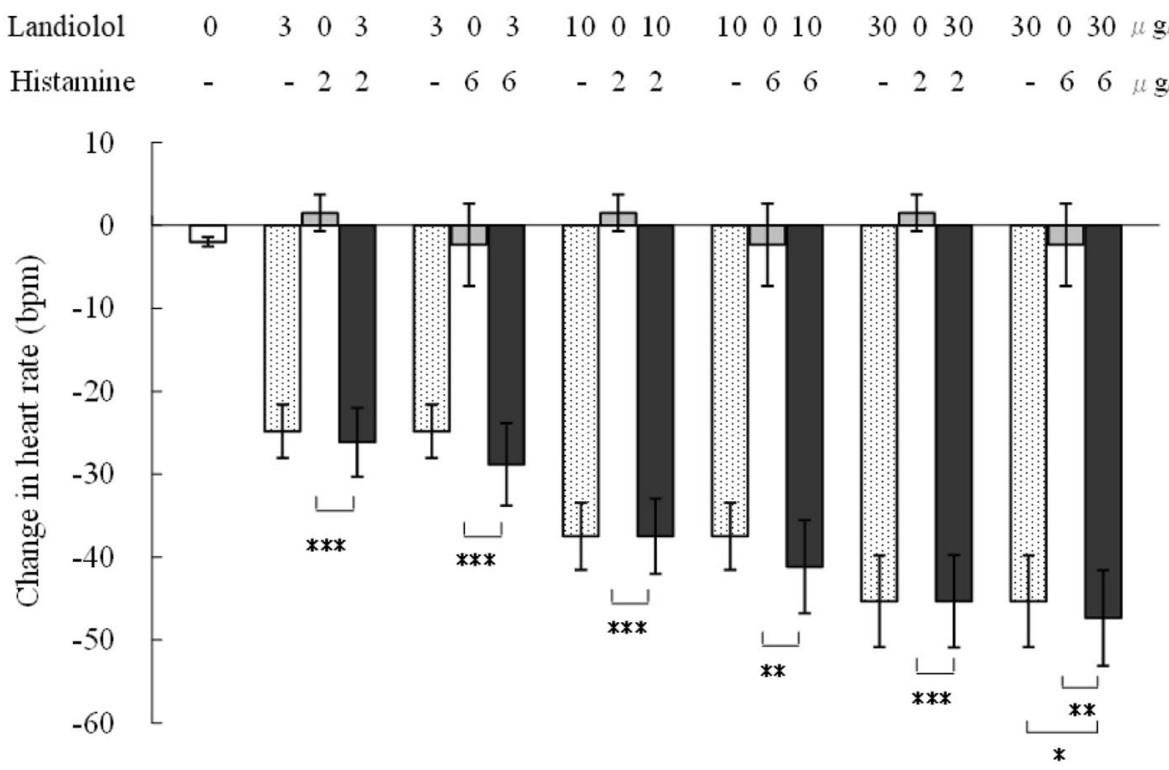

Fig. 3 Effect of landiolol on the action of histamine on cardiac contraction $(n=6) .{ }^{*} * P<0.01$; $* * * P<0.001$ (histamine vs landiolol and histamine; paired $t$-test). $\mathrm{LVdP} / \mathrm{d} t_{\max }$ represents the indicator of cardiac contraction

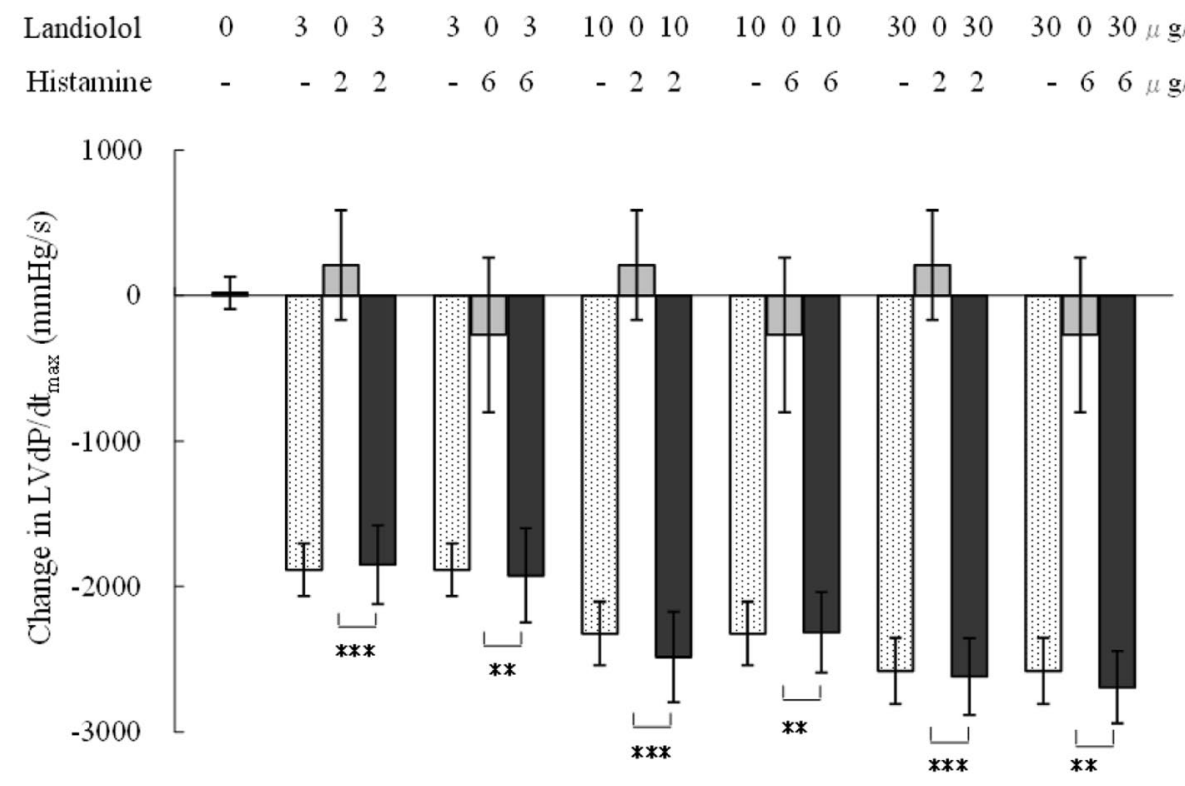

in mean blood pressure were $-32.7 \pm 4.7 \mathrm{mmHg}$ with $2 \mu \mathrm{g} / \mathrm{kg}$ of histamine and $30 \mu \mathrm{g} / \mathrm{kg} / \mathrm{min}$ of landiolol and $64.0 \pm 7.7 \mathrm{mmHg}$ with $6 \mu \mathrm{g} / \mathrm{kg}$ of histamine and $30 \mu \mathrm{g} / \mathrm{kg} /$ min of landiolol; these changes were equivalent to $25 \%$ and $19 \%$ enhancement, respectively.

As shown in Fig. 2, histamine ( 2 and $6 \mu \mathrm{g} / \mathrm{kg}$ ) exerted no apparent effect on heart rate. Landiolol (3,10, and $30 \mu \mathrm{g} / \mathrm{kg} /$ min) decreased heart rate in a dose-dependent manner, i.e., $-24.8 \pm 3.2,-37.5 \pm 4.1$, and $-45.3 \pm 5.5 \mathrm{bpm}$, respectively. The change in heart rate induced by the combination of histamine $(6 \mu \mathrm{g} / \mathrm{kg})$ and landiolol $(30 \mu \mathrm{g} / \mathrm{kg} / \mathrm{min})$ was $-47.3 \pm 5.8 \mathrm{bpm}$. Thus, use of the drugs in combination significantly enhanced their heart rate-lowering effect, albeit by as little as $4 \%$, compared with that of landiolol alone.

As shown in Fig. 3, histamine ( 2 and $6 \mu \mathrm{g} / \mathrm{kg}$ ) enhanced cardiac contraction in three of the six subjects but diminished cardiac contraction in the other three. Landiolol ( 3,10 , and $30 \mu \mathrm{g} / \mathrm{kg} / \mathrm{min}$ ) diminished cardiac contraction in a dose-proportional manner; changes in LVdP/ $\mathrm{d} t_{\max }$ were $-1884.2 \pm 181.3,-2322.7 \pm 218.8$, and $-2580.2 \pm 227.6 \mathrm{mmHg} / \mathrm{s}$, respectively. The combination of histamine and landiolol diminished cardiac contraction, but no difference was observed relative to the use of landiolol alone. 


\subsection{Effect of Landiolol on Antagonism of Histamine by Epinephrine}

In dogs under pentobarbital anesthesia, pre-histamine mean blood pressure, heart rate, and cardiac contraction ( $\mathrm{LVdP} /$ $\left.\mathrm{d} t_{\max }\right)$ values were $137.3 \pm 1.9 \mathrm{mmHg}, 177.7 \pm 6.3 \mathrm{bpm}$, and $4262.2 \pm 291.7 \mathrm{mmHg} / \mathrm{s}$, respectively. The effects of landiolol on histamine-induced changes in mean blood pressure, heart rate, and cardiac contraction are shown in Figs. 4, 5, 6.

As shown in Fig. 4, histamine $(6 \mu \mathrm{g} / \mathrm{kg})$ decreased mean blood pressure in the absence of landiolol by $61.8 \pm 7.1 \mathrm{mmHg}$. When histamine and epinephrine $(0.3,1$, or $3 \mu \mathrm{g} / \mathrm{kg})$ were combined, the changes in mean blood pressure were $-50.5 \pm 6.1,-12.2 \pm 13.4$, and $38.8 \pm 10.3 \mathrm{mmHg}$, respectively. Epinephrine dose-dependently antagonized the mean blood pressure-lowering effect of histamine. The change in mean blood pressure induced by $10 \mu \mathrm{g} / \mathrm{kg} / \mathrm{min}$ landiolol alone was $-5.2 \pm 4.9 \mathrm{mmHg}$. Histamine $(6 \mu \mathrm{g} / \mathrm{kg})$ decreased mean blood pressure in the presence of landiolol $(10 \mu \mathrm{g} / \mathrm{kg} / \mathrm{min})$ by $64.7 \pm 7.0 \mathrm{mmHg}$. When histamine and epinephrine $(0.3,1$, or $3 \mu \mathrm{g} / \mathrm{kg})$ were combined, the changes in mean blood pressure were $-52.0 \pm 7.9,-24.5 \pm 11.3$, and $24.2 \pm 9.9 \mathrm{mmHg}$, respectively. Thus, in the presence of landiolol, epinephrine also dose-dependently antagonized the mean blood pressurelowering effect of histamine. However, the antagonistic effect of epinephrine ( 1 or $3 \mu \mathrm{g} / \mathrm{kg}$ ) on histamine-induced mean blood pressure reduction was significantly inhibited by concomitant administration of landiolol. It should be noted that increasing the dose of epinephrine restored mean blood pressure to greater than pre-histamine levels, even with concomitant use of landiolol.

As shown in Fig. 5, histamine (6 $\mu \mathrm{g} / \mathrm{kg}$ ) exerted no apparent effect on heart rate in the absence of landiolol, with a

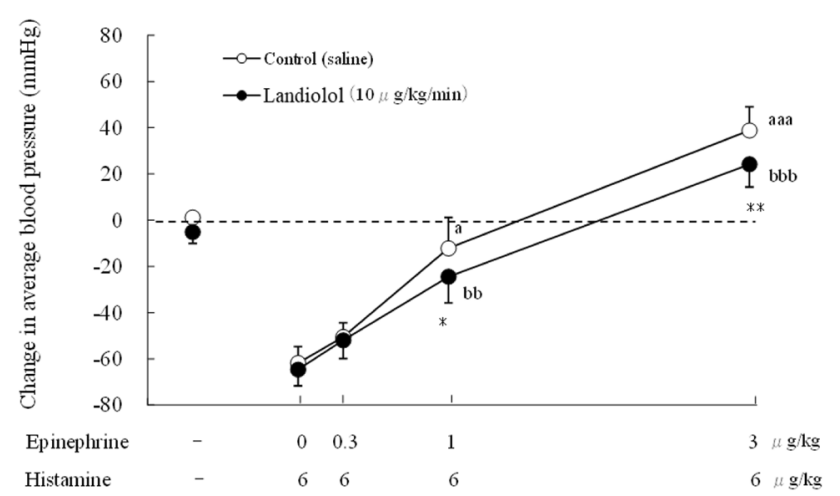

Fig. 4 Effect of landiolol on the action of epinephrine on blood pressure $(n=6)$. a: $P<0.05$; aaa: $P<0.001$ (histamine vs histamine and epinephrine; paired $t$-test); bb: $P<0.01$; bbb: $P<0.001$ (landiolol and histamine vs landiolol, histamine, and epinephrine; paired $t$-test); $* P<0.05 ; * * P<0.01$ (histamine and epinephrine vs landiolol, histamine, and epinephrine; paired $t$-test)

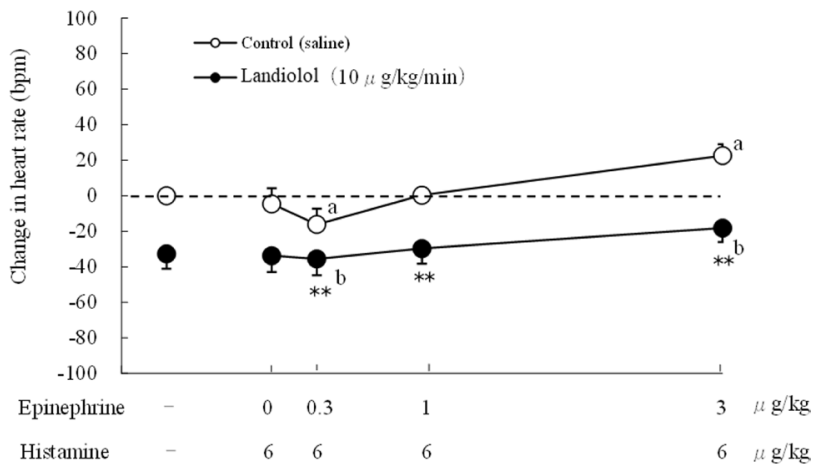

Fig. 5 Effect of landiolol on the action of epinephrine on heart rate $(n=6) .3 \mathrm{a}: P<0.05$ (histamine vs histamine and epinephrine; paired $t$-test); b: $P<0.05$ (landiolol and histamine vs landiolol, histamine, and epinephrine; paired $t$-test); $* * P<0.01$ (histamine and epinephrine vs landiolol, histamine and epinephrine; paired $t$-test)

change of only $-4.5 \pm 8.7 \mathrm{bpm}$. The changes in mean heart rate induced by combined administration of histamine and epinephrine $(0.3,1$, or $3 \mu \mathrm{g} / \mathrm{kg})$ were $-16.2 \pm 8.8,0.3 \pm 4.3$, and $22.7 \pm 6.2 \mathrm{bpm}$, respectively. Concomitant epinephrine $(3 \mu \mathrm{g} / \mathrm{kg})$ administration significantly increased heart rate. Landiolol alone $(10 \mu \mathrm{g} / \mathrm{kg} / \mathrm{min})$ decreased heart rate by $32.7 \pm 8.3 \mathrm{bpm}$. In the presence of landiolol, the change in heart rate induced by histamine $(6 \mu \mathrm{g} / \mathrm{kg})$ was $-33.7 \pm 9.3$ $\mathrm{bpm}$. Changes in heart rate induced by combined administration of histamine and epinephrine $(0.3,1$, or $3 \mu \mathrm{g} / \mathrm{kg})$ were $-35.5 \pm 9.2,-29.7 \pm 8.5$, and $-18.2 \pm 7.9 \mathrm{bpm}$, respectively. Concomitant epinephrine $(3 \mu \mathrm{g} / \mathrm{kg})$ significantly increased heart rate even in the presence of landiolol. Additionally, the heart rate-increasing action of combined

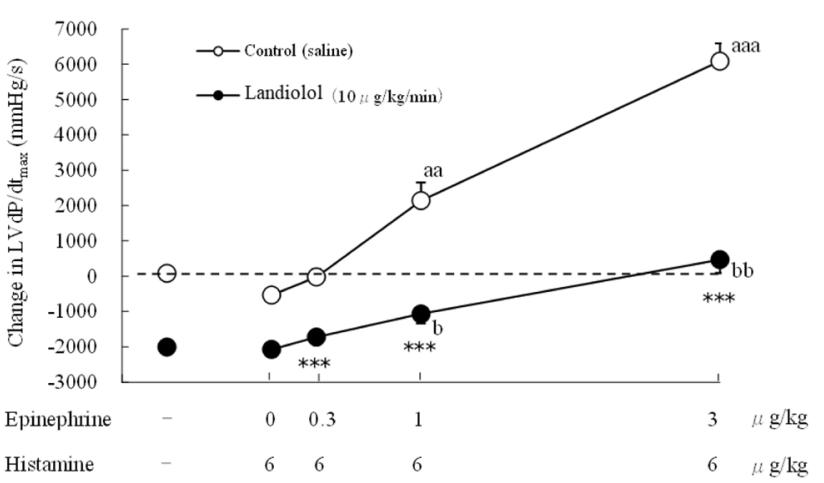

Fig. 6 Effect of landiolol on the action of epinephrine on cardiac contraction $(n=6)$. aa: $P<0.01$; aaa: $P<0.001$ (histamine vs histamine and epinephrine; paired $t$-test); b: $P<0.05$; bb: $P<0.01$ (landiolol and histamine vs landiolol, histamine, and epinephrine, paired $t$-test); $* * * * P<0.001$ (histamine and epinephrine vs landiolol, histamine, and epinephrine; paired $t$-test). $\mathrm{LVdP} / \mathrm{d} t_{\max }$ represents the indicator of cardiac contraction 
histamine and epinephrine was significantly inhibited by concomitant administration of landiolol.

As shown in Fig. 6, histamine $(6 \mu \mathrm{g} / \mathrm{kg})$ decreased cardiac contraction in the absence of landiolol. The change in LVdP/ $\mathrm{d} t_{\max }$ was $-532.7 \pm 178.3 \mathrm{mmHg} / \mathrm{s}$. The changes in LVdP/ $\mathrm{d} t_{\max }$ induced by combined administration of histamine and epinephrine $(0.3,1$, or $3 \mu \mathrm{g} / \mathrm{kg})$ were $-22.8 \pm 223.2$, $2141.7 \pm 513.1$, and $6088.3 \pm 499.1 \mathrm{mmHg} / \mathrm{s}$, respectively. Epinephrine antagonized histamine-induced reduction in cardiac contraction in a dose-proportional manner. Landiolol alone $(10 \mu \mathrm{g} / \mathrm{kg} / \mathrm{min})$ diminished cardiac contraction, with a change in $\mathrm{LVdP} / \mathrm{d} t_{\max }$ of $-2003.0 \pm 197.0 \mathrm{mmHg} / \mathrm{s}$.

In the presence of landiolol, histamine $(6 \mu \mathrm{g} / \mathrm{kg})$-induced change in $\mathrm{LVdP} / \mathrm{d} t_{\max }$ was $-2073.8 \pm 209.4 \mathrm{mmHg} / \mathrm{s}$.
The changes in $\mathrm{LVdP} / \mathrm{d} t_{\max }$ induced by a combined administration of histamine and epinephrine $(0.3,1$, or $3 \mu \mathrm{g} / \mathrm{kg}$ ) were $-1724.3 \pm 178.7,-1065.5 \pm 269.8$, and $468.2 \pm 381.0 \mathrm{mmHg} / \mathrm{s}$, respectively; epinephrine also antagonized the ability of histamine to diminish cardiac contraction in a dose-proportional manner in the presence of landiolol. However, the antagonistic effect of epinephrine ( 1 or $3 \mu \mathrm{g} / \mathrm{kg}$ ) on the ability of histamine to diminish cardiac contraction was significantly inhibited by concomitant administration of landiolol. Increasing the epinephrine dose resulted in restoration of cardiac contraction to greater than pre-histamine levels, even with concomitant landiolol.
Fig. 7 Effect of landiolol on the action to glucagon on cardiac contraction $(n=6)$. $* * * P<0.001$ (histamine vs glucagon and histamine; paired $t$-test), ${ }^{\# \#} P<0.01$ (glucagon and histamine vs landiolol, glucagon, and histamine; paired $t$-test). $\mathrm{LVdP} / \mathrm{d} t_{\max }$ represents the indicator of cardiac contraction

Fig. 8 Effect of landiolol on the action of glucagon on heart rate $(n=6) . * * * P<0.001$ (histamine vs glucagon and histamine; paired $t$-test)

$\begin{array}{lcccccc}\text { Landiolol } & 0 & 0 & 3 & 3 & 3 \mu \mathrm{g} / \mathrm{kg} / \mathrm{min} \\ \text { Glucagon } & 0 & 0.3 & 0.3 & 3 & 30 \mu \mathrm{g} / \mathrm{kg} / \mathrm{min} \\ \text { Histamine } & 6 & 6 & 6 & 6 & 6 \mu \mathrm{g} / \mathrm{kg}\end{array}$
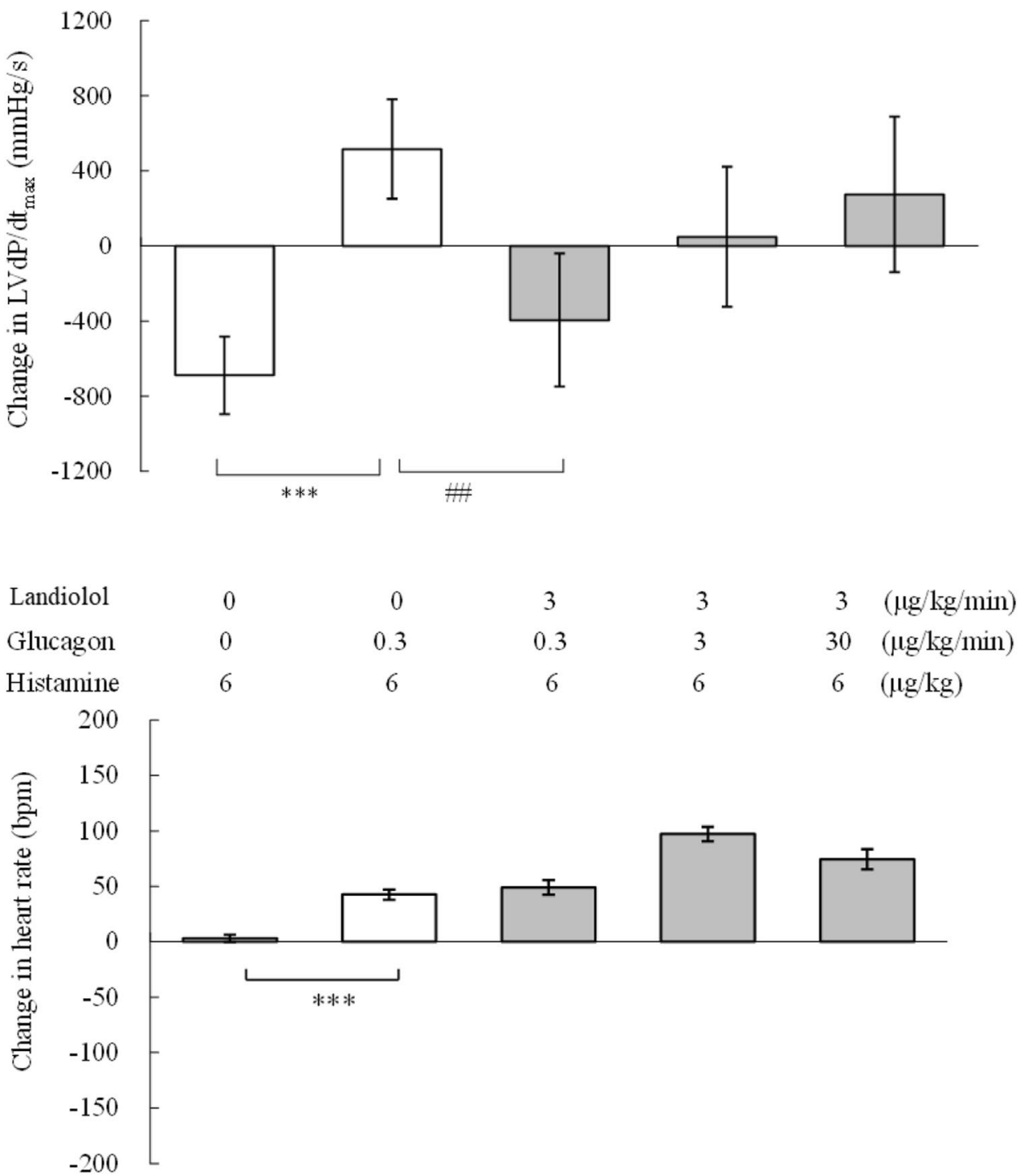


\subsection{Effect of Landiolol on Antagonism of Histamine by Glucagon}

In dogs under pentobarbital anesthesia, pre-histamine values for cardiac contraction $\left(\mathrm{LVdP} / \mathrm{d} t_{\max }\right)$ and heart rate were $3969.0 \pm 382.8 \mathrm{mmHg} / \mathrm{s}$ and $159.3 \pm 5.1 \mathrm{bpm}$, respectively. The effects of landiolol on glucagon-mediated antagonism of changes in cardiac contraction and heart rate induced by histamine are shown in Figs. 7 and 8.

As shown in Fig. 7, histamine alone $(6 \mu \mathrm{g} / \mathrm{kg})$ reduced cardiac contraction, with a change in $\mathrm{LVdP} / \mathrm{d} t_{\max }$ of $-688.8 \pm 206.4 \mathrm{mmHg} / \mathrm{s}$. The change in $\mathrm{LVdP} / \mathrm{d} t_{\max }$ induced by combined administration of histamine and glucagon $(0.3 \mu \mathrm{g} / \mathrm{kg} / \mathrm{min})$ was $515.7 \pm 264.9 \mathrm{mmHg} / \mathrm{s}$. Glucagon antagonized histamine-mediated diminution of cardiac contraction. The changes in $\mathrm{LVdP} / \mathrm{d} t_{\max }$ induced by combined administration of histamine and glucagon $(0.3,3$, or $30 \mu \mathrm{g} /$ $\mathrm{kg} / \mathrm{min}$ ) in the presence of landiolol were $-394.8 \pm 354.4$, $48.7 \pm 372.9$, and $274.5 \pm 414.1 \mathrm{mmHg} / \mathrm{s}$, respectively. The antagonistic effect of glucagon $(0.3 \mu \mathrm{g} / \mathrm{kg} / \mathrm{min})$ on diminution of cardiac contraction by histamine was significantly inhibited. However, increasing the dose of glucagon to 3 or $30 \mu \mathrm{g} / \mathrm{kg} / \mathrm{min}$ returned cardiac contraction to greater than pre-histamine levels, even with concomitant landiolol.

As shown in Fig. 8, histamine ( $6 \mu \mathrm{g} / \mathrm{kg}$ ) exerted no apparent effect on heart rate, with a change of only $3.2 \pm 3.4 \mathrm{bpm}$. The change in heart rate induced by a combination of histamine and glucagon $(0.3 \mu \mathrm{g} / \mathrm{kg} / \mathrm{min})$ was $42.5 \pm 4.7 \mathrm{bpm}$. Thus, concomitant glucagon $(0.3 \mu \mathrm{g} / \mathrm{kg} / \mathrm{min})$ significantly increases heart rate. In the presence of landiolol $(3 \mu \mathrm{g} / \mathrm{kg} /$ min), the change in heart rate induced by combined administration of histamine and glucagon $(0.3 \mu \mathrm{g} / \mathrm{kg} / \mathrm{min})$ was $49.0 \pm 6.6 \mathrm{bpm}$, indicating that concomitant landiolol had no significant effect on the heart rate-increasing action of combined histamine and glucagon.

\section{Discussion}

Anaphylactic shock in response to contrast media can be fatal and is characterized by symptoms including excessive loss of blood pressure due to chemical mediators such as histamine secreted from mast cells. To evaluate patient clinical conditions and the effect of landiolol hydrochloride treatment on contrast media-induced anaphylactic shock treatment response, we reviewed the effects of landiolol on changes in blood pressure, heart rate, and cardiac contraction induced by histamine; antagonism of histamine action by epinephrine (decreased blood pressure and diminished cardiac contraction); and antagonism of histamine action by glucagon (diminished cardiac contraction).

A comparison between histamine alone and combined histamine and landiolol administration revealed that the blood pressure-lowering action of histamine was additively or synergistically enhanced by concomitant administration of landiolol. Histamine alone exerted no apparent effect on heart rate or cardiac contraction. The heart rate-lowering action was slightly enhanced, albeit as little as $4 \%$, by concomitant landiolol, but this occurred only at high doses. Therefore, we predicted that landiolol would exert no effect on heart rate or cardiac contraction, in contrast to its effect on blood pressure. Further, landiolol-mediated enhancement of the blood pressure-lowering action of histamine could be attributed to diminished cardiac contraction resulting from $\beta_{1}$-blocking action. We reviewed the effect of concomitant landiolol administration on epinephrine-mediated antagonism of histamine-induced changes in blood pressure, heart rate, and cardiac contraction and confirmed that landiolol inhibited this antagonism of histamine by epinephrine (i.e., by decreasing mean blood pressure and cardiac contraction). The effect of landiolol on epinephrine-mediated histamine antagonism was weak in terms of blood pressure but strong in terms of cardiac contraction, suggesting a substantial effect of $\beta_{1}$ receptor-blocking action. By reviewing the effect of concomitant landiolol administration on antagonism of histamine action by glucagon (i.e., by diminishing cardiac contraction), we confirmed that landiolol inhibited this antagonistic effect of glucagon. However, we also confirmed that increasing the glucagon dose restored cardiac contraction to greater than pre-histamine levels, even with concomitant use of landiolol.

We conclude that landiolol enhances the blood pressurelowering effect of histamine. Hence, blood pressure reduction may be severe in the presence of landiolol in cases of anaphylactic shock due to contrast media. However, the effect of landiolol disappears rapidly, suggesting that it contributes to shock for a shorter duration than other $\beta$-blockers. Additionally, landiolol weakened the antagonistic effects of epinephrine and glucagon, the therapeutic agents used in cases of contrast media-induced shock. However, mean blood pressure and cardiac contraction were restored by elevated epinephrine and glucagon doses to greater than prehistamine levels, even with concomitant landiolol. Therefore, if shock occurs during the use of landiolol, it can be treated by increasing epinephrine and glucagon levels. This suggests that concomitant use of landiolol does not excessively increase the risk posed by anaphylactic shock due to contrast media for CCTA.

This study has several limitations. First, it is extremely difficult to assess the effect of $\beta$-blockers in combination with adrenaline and glucagon in patients with contrast media-induced anaphylactic shock. Hence, we conducted this research in animal (dog) models treated with histamine, which is released during anaphylactic shock.

In addition, as landiolol is a short-acting $\beta 1$-selective blocker, we selected continuous administration of landiolol, 
instead of single-dose administration, to appropriately evaluate the effect of concomitant use of landiolol with epinephrine or glucagon on hemodynamics. We selected pentobarbital anesthesia because, in a previous review of anesthetic conditions, heart rate reduction by landiolol in clinical settings could not be clearly confirmed with nitrous oxide or isoflurane, which independently reduced the heart rate. Landiolol, which is administered to reduce the heart rate during CCTA, causes an approximately $20 \%$ reduction within 3-5 min after administration ${ }^{10-13}$. Thus, pentobarbital, which activates the sympathetic nervous system, fits the clinical settings in which contrast media and landiolol are administered in combination. A prior study in dogs revealed no enhancement of circulatory organ-related effects (heart rate reduction, $\mathrm{PR}$ prolongation, blood pressure reduction, or $\mathrm{LVdP} / \mathrm{d} t_{\max }$ reduction) with combined iopamidol, a nonionic contrast medium, and landiolol (data not shown). The clinical incidence of contrast media-induced shock is below $0.1 \%$, which cannot be reproduced in preclinical settings from both feasibility and ethical perspectives. As contrast media-induced histamine release from mast cells is considered a factor in the development of shock (anaphylactic shock) in response to contrast media, this model of histamine-induced shock was selected for evaluation in this study.

This research was also conducted with the intravenous $\beta$-blocker landiolol hydrochloride, which is used concomitantly with contrast media in CCTA in Japan. Accordingly, further research using other $\beta$-blockers is required.

\section{Conclusions}

In patients receiving landiolol during CCTA, deterioration in hemodynamic parameters during anaphylactic shock can be mitigated by increasing the dose of epinephrine or glucagon. Therefore, clinicians should prepare appropriate amounts of epinephrine and glucagon prior to CCTA.

Acknowledgements This study was supported by Ono Pharmaceutical Co., Ltd. The authors thank Yuko Sano for providing editorial support.

\section{Declarations}

Funding This study was funded by Ono Pharmaceutical Co., Ltd.

Conflict of interest Masaharu Hirano has no competing financial interests. Tatsuaki Okamura, Tetsuji Nagano, Shigeyuki Nonaka, and Tsutomu Shiroya are employees of Ono Pharmaceutical Co., Ltd.

Ethics approval Not applicable.

Consent to participate Not applicable.
Availability of data and material Not applicable.

Code availability Not applicable.

Author contributions $\mathrm{MH}$ and $\mathrm{TO}$ wrote the manuscript. TN, SN, and TS prepared the figures. All authors have reviewed the manuscript.

Open Access This article is licensed under a Creative Commons Attribution-NonCommercial 4.0 International License, which permits any non-commercial use, sharing, adaptation, distribution and reproduction in any medium or format, as long as you give appropriate credit to the original author(s) and the source, provide a link to the Creative Commons licence, and indicate if changes were made. The images or other third party material in this article are included in the article's Creative Commons licence, unless indicated otherwise in a credit line to the material. If material is not included in the article's Creative Commons licence and your intended use is not permitted by statutory regulation or exceeds the permitted use, you will need to obtain permission directly from the copyright holder. To view a copy of this licence, visit http://creativecommons.org/licenses/by-nc/4.0/.

\section{References}

1. Antman EM, Anbe DT, Armstrong PW, et al. ACC/AHA guidelines for the management of patients with ST-elevation myocardial infarction: a report of the American College of Cardiology/American Heart Association Task Force on Practice Guidelines (Committee to Revise the 1999 Guidelines for the Management of Patients with Acute Myocardial Infarction). Circulation. 2004;110:e82-292.

2. Amsterdam EA, Wenger NK, Brindis RG, et al. 2014 AHA/ACC guideline for the management of patients with non-ST-elevation acute coronary syndromes: a report of the American College of Cardiology/American Heart Association Task Force on Practice Guidelines. Circulation. 2014;130:e344-426.

3. Ibánez B, James S, Agewall S, et al. 2017 ESC guidelines for the management of acute myocardial infarction in patients presenting with ST-segment elevation: the Task Force for the Management of Acute Myocardial Infarction in Patients Presenting with ST-Segment Elevation of the European Society of Cardiology (ESC). Eur Heart J. 2018;39:119-77.

4. Hamm CW, Bassand JP, Agewall S, et al. ESC guidelines for the management of acute coronary syndromes in patients presenting without persistent ST-segment elevation: the Task Force for the Management of Acute Coronary Syndromes (ACS) in Patients Presenting Without Persistent ST-Segment Elevation of the European Society of Cardiology (ESC). Eur Heart J. 2011;32:2999-3054.

5. Bluemke DA, Achenbach S, Budoff M, et al. Noninvasive coronary artery imaging: magnetic resonance angiography and multidetector computed tomography angiography: a scientific statement from the american heart association committee on cardiovascular imaging and intervention of the council on cardiovascular radiology and intervention, and the councils on clinical cardiology and cardiovascular disease in the young. Circulation. 2008;118:586-606.

6. Mark DB, Berman DS, Budoff MJ, et al. ACCF/ACR/AHA/NASCI/ SAIP/SCAI/SCCT 2010 expert consensus document on coronary computed tomographic angiography: a report of the American College of Cardiology Foundation Task Force on Expert Consensus Documents. Circulation. 2010;121:2509-43.

7. Mollet NR, Cademartiri F, van Mieghem CA, et al. High-resolution spiral computed tomography coronary angiography in patients referred for diagnostic conventional coronary angiography. Circulation. 2005;112:2318-23.

Consent for publication Not applicable. 
8. Miller JM, Rochitte CE, Dewey M, et al. Diagnostic performance of coronary angiography by 64-row CT. N Engl J Med. 2008;359:2324-36.

9. Nakashima M, Kanemaru M. Phase I study of ONO-1101, a new ultra short acting $\beta 1$-blocking agent in healthy volunteers [in Japanese]. J Clin Ther Med. 2000;16:1531-6.

10. Hirano M, Hara K, Ikari Y, et al. Dose-finding study of landiolol hydrochloride: a short-acting $\beta 1$-blocker for controlling heart rate during coronary computed-tomography angiography in Japan. Adv Ther. 2013;30:803-18.

11. Jinzaki M, Hirano M, Hara K, et al. A randomized, double-blind, placebo-controlled, phase II dose-finding study of the short acting $\beta 1$-blocker, landiolol hydrochloride, in patients with suspected ischemic cardiac disease. Int J Cardiovasc Imaging. 2013;29:7-20.

12. Hirano M, Yamashina A, Hara K, et al. A randomized, double-blind, placebo-controlled, phase III study of the short-acting $\beta 1$-adrenergic receptor blocker landiolol hydrochloride for coronary computed tomography angiography in Japanese patients with suspected ischemic cardiac disease. Clin Drug Investig. 2014;34:53-62.

13. Hirano M, Yamashina A, Hara K, et al. A multicenter, openlabel study of an intravenous short-acting $\beta 1$-adrenergic receptor antagonist landiolol hydrochloride for coronary computed tomography angiography by 16 -slice multi-detector computed tomography in Japanese patients with suspected ischemic cardiac disease. Drugs R\&D. 2014;14:185-94.

14. Katayama H, Yamaguchi K, Kozuka T, et al. Adverse reactions to ionic and nonionic contrast media: a report from the Japanese Committee on the Safety of Contrast Media. Radiology. 1990;175:621-8.

15. Lasser EC, Walters A, Reuter SR, Lang J. Histamine release by contrast media. Radiology. 1971;100:683-6.

16. Pinet A, Corot C, Biot N, Eloy R. Evaluation of histamine release following intravenous injection of ionic and nonionic contrast media. Investig Radiol. 1988;23:S174-7.

17. Simons FE, Ardusso LR, Bilò MB, et al. World allergy organization guidelines for the assessment and management of anaphylaxis. World Allergy Organ J. 2011;4:13-37.

18. Lang DM, Alpern MB, Visintainer PF, Smith ST. Increased risk for anaphylactoid reaction from contrast media in patients on beta-adrenergic blockers or with asthma. Ann Intern Med. 1991;115:270-6. 